\title{
Shoulder pain and disability index: its effectiveness and reliability in an outpatient setting in Indian population
}

\author{
Sukumar Nayak P. T. ${ }^{1}$, Manjunatha A. ${ }^{2 *}$
}

\author{
${ }^{1}$ Department of Physiotherapy, Garden City University, Karnataka, India \\ ${ }^{2}$ Department of Orthopaedics, Kodagu Institute of Medical Sciences, Karnataka, India
}

Received: 11 May 2020

Revised: 24 May 2020

Accepted: 27 May 2020

\author{
*Correspondence: \\ Dr. Manjunatha A., \\ E-mail: dr.anjan4u@gmail.com
}

Copyright: () the author(s), publisher and licensee Medip Academy. This is an open-access article distributed under the terms of the Creative Commons Attribution Non-Commercial License, which permits unrestricted non-commercial use, distribution, and reproduction in any medium, provided the original work is properly cited.

\begin{abstract}
Background: One of the most common joints to be treated in the clinic is the shoulder joint. An orthopedic surgeon and physical therapists should be knowledgeable about the proper assessment of the shoulder joint to effectively evaluate and design a treatment program in shoulder pathologies. Shoulder pain and disability index (SPADI) is a questionnaire designed to measure pain and disability associated with shoulder pathologies in a clinical setting. SPADI's effectiveness as a tool needed to be validated in Indian population hence this study. The objectives of this study were to measure effectiveness of SPADI in our setting and to measure the reliability and acceptability of SPADI in Indian population.

Methods: 60 patients with shoulder pain between the age of 25-50 years who attended the orthopaedic OPD during the time period of April 2017 to April 2018 were included. The subjects were evaluated with SPADI and oxford shoulder score (OSS) questionnaires. The data was analyzed by paired sample T test and alpha coefficient level.

Results: The data statistically analysed revealed that the scales are reliable as the Cronbach's alpha was high $(>0.7)$ and was effective to measure the pain and disability of the shoulder joint in our clinical set up.

Conclusions: It can be concluded from our statistical analysis that both SPADI and OSS are equally effective tools in measuring pain and disability in our clinical set up, the only difference being that SPADI is operationally very simple and lucid for our population.
\end{abstract}

Keywords: SPADI, Shoulder pain, OSS

\section{INTRODUCTION}

Shoulder pain is a very common musculoskeletal disorder seen in clinical practice. Its prevalence ranks third after low back pain and neck pain. ${ }^{1}$ A number of groups have developed self-administered shoulder pain and disability questionnaires since the 1990s. ${ }^{2-10}$ They include the shoulder pain and disability index (SPADI), simple shoulder test (SST), United Kingdom shoulder disability questionnaire (SDQ-UK), American shoulder and elbow surgeon's shoulder assessment form (M-
ASES), oxford shoulder score (OSS), subjective shoulder rating system (SSRS), shoulder rating questionnaire (SRQ), and Dutch shoulder disability questionnaire (SDQ-NL) and all these are self-completed, non-disease-specific shoulder questionnaires available in English and published in peer reviewed journals since $1990 .^{2-11}$ The quantification of pain through these questionnaires, helps in evaluation of novel therapies and in the evaluation of outcome measures of impairment and disability. ${ }^{12}$ 
The shoulder pain and disability index (SPADI) was developed by Roach et al and initially validated in a sample of 37 male patients with shoulder pathology recruited from an ambulatory care clinic. ${ }^{2}$ It was designed as a self-administered questionnaire to measure the pain and disability associated with shoulder pathology in the outpatient setting. It consists of 13 items in 2 domains; pain (5 items) and disability (8 items), scored on a visual Analog scales, ranging from 0 to $10(0=$ no pain/no difficulty and $10=$ worst pain imaginable/so difficult required help). Each item score is equally-weighted, then added for a total percentage score from 0 to $100(0=$ best and $100=$ worst $).{ }^{2}$ SPADI has been validated in groups like those with adhesive capsulitis and patients recruited from primary care with shoulder pain and following shoulder arthroplasty. ${ }^{13-15}$ It has also been found to be responsive to change in a variety of clinical settings like those of shoulder arthroplasty, treatment for adhesive capsulitis and sub acromial impingement. ${ }^{14-20}$ SPADI's completion time recorded was between 2 and 5 minutes, and its scoring system was relatively easy ${ }^{13,11}$ Many of the studies have established validity by correlating the SPADI scores with generic questionnaires like short form 36 (SF-36) and sickness impact profile (SIP), or with another shoulderspecific instrument (e.g. DASH). This is defined as the convergent validity. ${ }^{17,21-23}$

Systematic reviews conducted to investigate the psychometric evidence of SPADI have confirmed its high reliability in terms of its validity in a range of clinical setting and responsiveness to change. They have proven SPADI to be useful in both clinical and research settings. ${ }^{24,25}$ But it is seen that the clinicometric properties of a questionnaire may vary among different setting and populations. ${ }^{26}$ There has been no studies done to prove the effectiveness of SPADI in an Indian population visiting orthopedic outpatient setting by random sampling. So, the aim of our study was to study the effectiveness of SPADI with OSS which is another shoulder specific instrument and also to study its reliability in our population.

\section{Objectives}

The objectives of the study were to measure effectiveness of shoulder pain and disability index (SPADI) in our setting and to measure the reliability and acceptability of SPADI in Indian population.

\section{METHODS}

In this study 60 patients who came to our orthopaedic outpatient clinic with shoulder pain between the time period of April 2017 to April 2018 were evaluated with SPADI and OSS questionnaire. The study was conducted in Srinivasa Multispecialty Hospital, Hoskote, Bangalore, after having got ethical clearance from the ethical committee in the hospital and also an informed written consent from the participants.

\section{Inclusion criteria}

Inclusion criteria were both male and female patients between the age 25-50 years of age were included. Patients with shoulder pathology due to trauma, metabolic causes like diabetes mellitus and due to degenerative changes were included.

\section{Exclusion criteria}

Exclusion criteria were age below 25 and above 50 years. Shoulder pain and disability due to neurological causes were excluded from this study.

The sample of the study was collected by simple randomization block design. All patients who self-reported to the outpatient set up were first evaluated by the orthopaedician. Patients who fitted our inclusion criteria were evaluated with both SPADI and OSS questionnaire.

In OSS there are totally 12 questions with 5 points response, lowest (best score) is 12 and highest (worse score) is 60 . Of the 12 questions 4 are pain related items $(33 \%)$ and 8 are disability related items making upto $67 \%$.

SPADI has total of 13 questions scored on a visual analog scale ranging from $0-10.5$ questions are pain related $(38.46 \%)$ and 8 are disability related $(61.53 \%)$. Thus, both OSS and SPADI are almost similar in terms of number of questions and in terms of the percentage of their individual categorized items.

The subjects were asked to fill the questionnaire, and due care was taken to avoid the omission of any questions. The filled in questionnaires were collected and filed.

In SPADI we have 5 pain questionnaires so the total pain score is calculated by dividing the obtained pain score by 50 and multiplied by 100 .

$\frac{\text { Total pain score }}{50 \times 100}=\%$

Similarly, the total disability score is calculated by dividing the obtained disability score by 80 and multiplied by 100 .

$\frac{\text { Total disability score }}{80 \times 100}=\%$

The total SPADI score is calculated by dividing the obtained pain and disability score by 130 and multiplied by 100 .

$\underline{\text { Total SPADI score }}=\%$ $130 \times 100$

The OSS, has 4 items under pain domain rating from 1 to 5 so the total pain scale is calculated by dividing the obtained pain score by 20 and multiplied by 100 . 
$\frac{\text { Total pain score }}{20 \times 100}=\%$

Similarly, the total disability related score is calculated by dividing the obtained disability score by 40 and multiplied by 100 .

$\frac{\text { Total disability score }}{40 \times 100}=\%$

The total OSS score is calculated by dividing the both pain and ADL score by 60 and multiplied by 100 .

$\frac{\text { Total OSS score }}{60 \times 100}=\%$

\section{Statistical tools}

Paired sample T test was used to find out the effectiveness of SPADI and OSS and alpha coefficient levels for determining the reliability of the instruments used in this study.

\section{Ethical clearance}

Ethical clearance was obtained from the ethical committee of the hospital where study was done.

\section{RESULTS}

The raw data was filed and from this the standardized scores were obtained. The mean age in the study was 39.96 years; with male to female ratio was 19:11. The age distribution in numbers and gender distribution percentages are represented in (Figure 1 and 2) respectively. The diagnosis and side affected percentages are shown in (Figure 3 and 4).

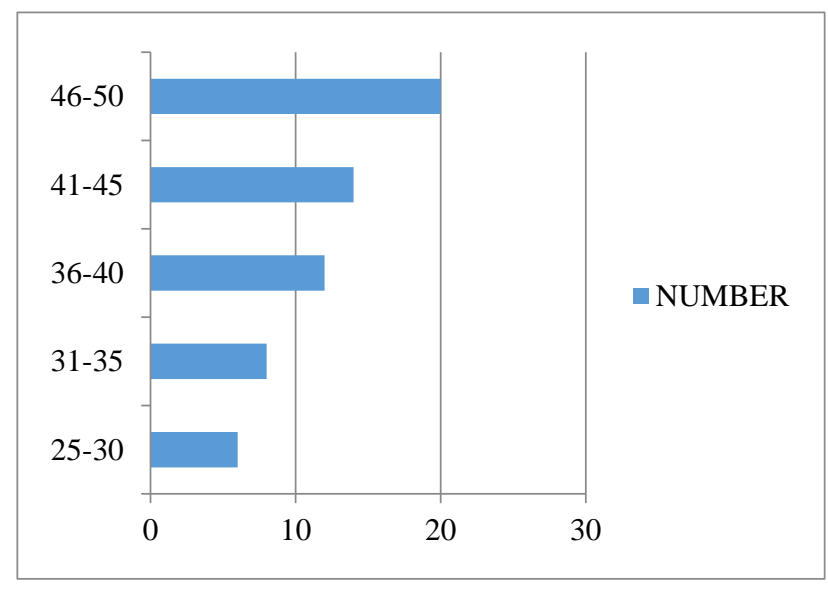

Figure 1: Age distribution in number among the study population.

\section{Paired sample t test}

Both SPADI and OSS methods are statistically significant. That is, the before and after values as captured by the two pairs SPADI 1, SPADI2 (Figure 5) and OSS1, OSS2 (Figure 6) seem statistically significant. $P$ value is less than 0.001 . Both methods seem equally effective as seen by almost identical $\mathrm{t}$ scores (Table 1).

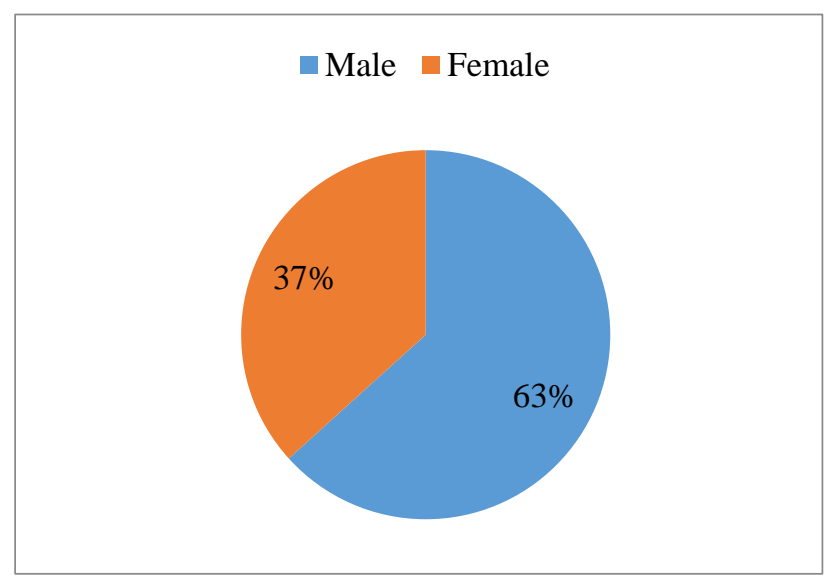

Figure 2: Gender distribution in percentage among the study population.

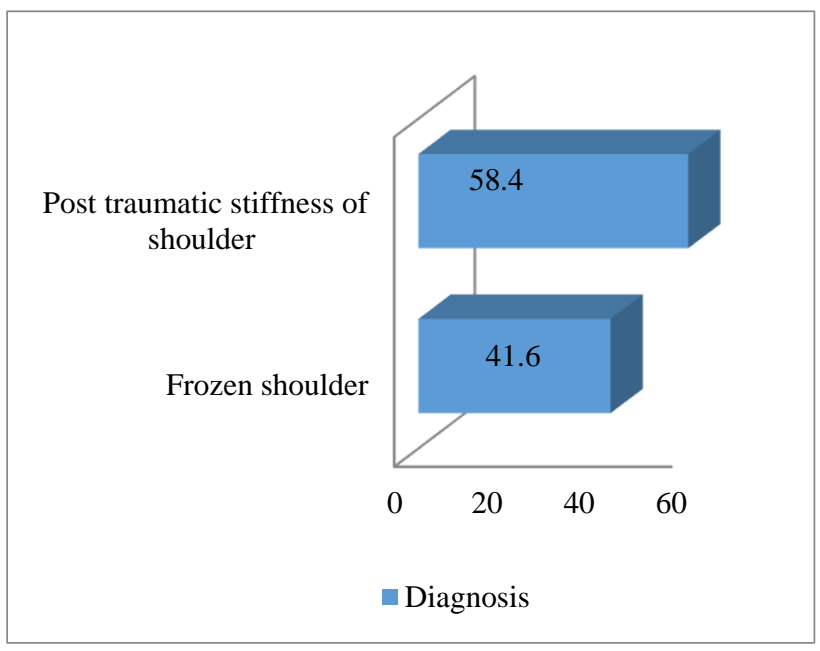

Figure 3: Diagnosis in study population.

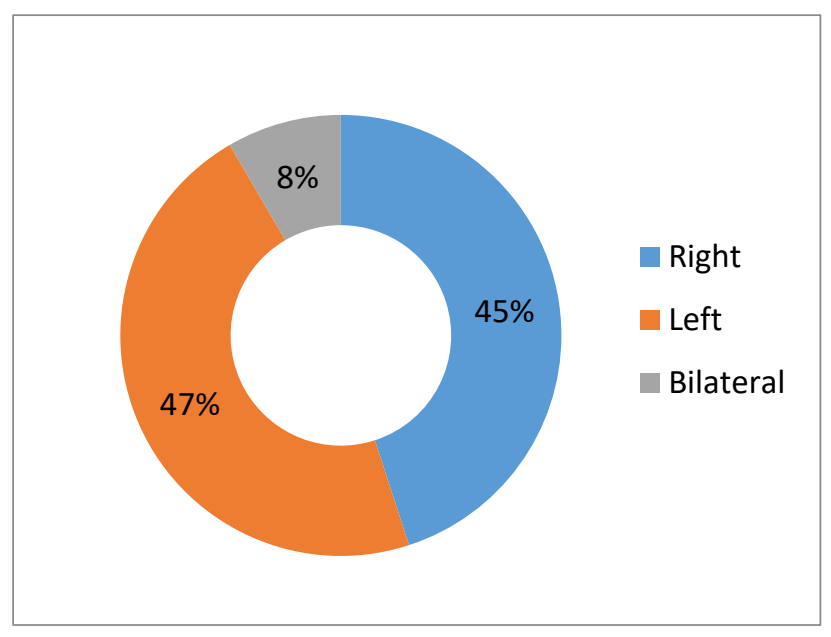

Figure 4: Side of shoulder affected in patients. 
Table 1: Results of paired sample $t$ test.

\begin{tabular}{|c|c|c|c|c|c|c|c|c|}
\hline \multicolumn{9}{|c|}{$95 \%$ confidence interval of the difference } \\
\hline & Mean & SD & SE mean & Lower & Upper & T value & df & Sig. (2-tailed) \\
\hline $\begin{array}{l}\text { Pair } 1 \text { SPADI1- } \\
\text { SAPDI2 }\end{array}$ & -10.00083 & 3.99864 & 0.51622 & -11.03379 & -8.96788 & -19.373 & 59 & 0.000 \\
\hline $\begin{array}{l}\text { Pair } 2 \text { OSS1- } \\
\text { OSS2 }\end{array}$ & -10.00200 & 4.00030 & 0.51644 & -11.03539 & -8.96861 & -19.363 & 59 & 0.000 \\
\hline
\end{tabular}

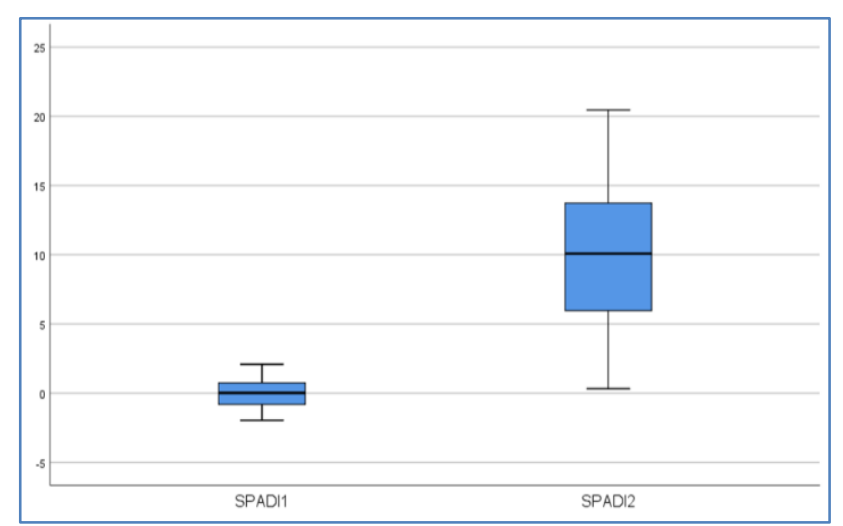

Figure 5: Effectiveness of SPADI.

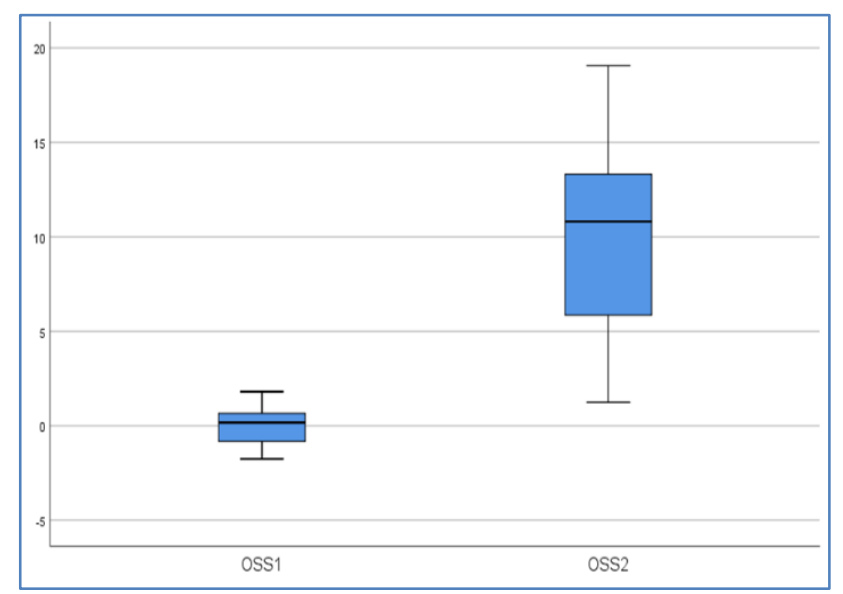

Figure 6: Effectiveness of OSS.

\section{Reliability analysis}

\section{Internal consistency reliability}

The reliability of the scales and their individual items were empirically examined through the calculation of Cronbach's alpha coefficients. Cronbach's alpha scores can be interpreted as the squared correlation between the score a subject obtains on a particular conceptual scale (the observed score) and the score that he or she would have obtained if questioned on all possible measurement items for the concept of interest (the true score). Alpha is interpreted as correlation coefficient; it ranges in values from 0.00 to 1.00. Generally, scales that obtain Alpha levels of 0.70 or greater are considered to be reliable. The alpha level obtained for the pain domain of SPADI is
0.8291 which is greater than 0.70 and is considered to be reliable in assessing the pain.

Similarly, the alpha level obtained for disability domain of SPADI is 0.7989 which is again greater than 0.70 and the reliability in assessing disability is proved. The alpha level obtained for the pain domain of OSS is 0.8847 which is greater than 0.70 and is considered to be reliable in assessing the pain. Similarly, the alpha level obtained for ADL impairment domain of OSS is 0.9131 which is greater than 0.70 and the reliability in assessing ADL is proved.

Paired sample $\mathrm{t}$ test shows identical $\mathrm{t}$-score for both the tests hence it can be deduced that both the instruments are of the same value with respect to measuring pain as well as disability in the Indian population. But there is a difference in respect of the two instruments in our population, where practically it is observed that SPADI looks to be quite convenient, understandable by people without any difficulty compared to the OSS. May be this aspect can be understood from the cultural point of view where a particular way of life has its own influence in making the people understand things better with a particular instrument. Mathematically and statistically, both the instruments look to be of the same importance but practically cultural ingredients influence their use.

\section{DISCUSSION}

In study conducted by Hill et al, 2011, patients were selected randomly from the community and in few more studies like that of Paul et al, Dermid et al and Williams et al, patients have been recruited via newspapers, advertisements, clinic posters or from primary care clinics. $^{27,11,14,15}$ In our study we have selected patients who presented in orthopedic outpatient set up with complaints of shoulder pain and disability.

The original study done by Roach et al, developed this questionnaire and studied on 37 male patients with shoulder pathology. Here the test-retest reliability of the total SPADI and subscale scores ranged from 0.63770.6552. SPADI total and subscale, negatively correlated with shoulder range of movements supporting the criterion validity of the index. This negative correlation indicated the SPADI delected changes in clinical status over short time intervals. The principal component factor analysis with and without varimax rotation supported the construct validity of the total SPADI and its subscale. ${ }^{2}$ 
Table 2: Internal consistency reliability by showing their Cronbach's alpha value in different studies.

\begin{tabular}{|c|c|c|c|c|c|}
\hline Roach et $\mathbf{a l}^{2}$ & Hill et $\mathbf{a l}^{27}$ & Jamnik et $a^{21}$ & Bicer et $a^{28}$ & Lacomba et al ${ }^{29}$ & Our \\
\hline $\begin{array}{l}\text { Total scale } \\
\text { range } 0.8604- \\
0.9507\end{array}$ & $\begin{array}{l}\text { Pain subscale } 0.85 \\
\text { disability subscale } \\
0.90\end{array}$ & $\begin{array}{l}\text { Pain subscale } \\
0.78 \text { disability } \\
\text { subscale } 0.90\end{array}$ & $\begin{array}{l}\text { Total scale } \\
0.94\end{array}$ & $\begin{array}{l}\text { Total scale } 0.965 \text { pain } \\
\text { subscale } 0.931 \text { disability } \\
\text { subscale } 0.953\end{array}$ & $\begin{array}{l}\text { Pain subscale } \\
0.8291 \text { disability } \\
\text { subscale } 0.7989\end{array}$ \\
\hline
\end{tabular}

A study by Hill et al 2011, which was a population-based study of people with shoulder symptoms, where about 3,206 patients participated. This study also found negative co relation between SPADI disability score and shoulder range of movement and also negative co relation between short form - 36 physical component score and SPADI disability scores. Principal component factor analysis was interpreted using varimax rotated, normalized factor loading, showed all of the pain items loaded on factor 2 with coefficient of 0.64 or over. All of the 8 disability items loaded on factor 1 with coefficient of over 0.58 . Therefore, factor 1 is interpreted as disability, and factor 2 is interpreted as pain. ${ }^{27}$

A study done by Jamnik et al 2008, to validate SPADI in Slovene version had a total of 52 participants; it showed test-retest reliability with intraclass correlation coefficient SPADI 0.94, pain subscale 0.89 and disability subscale 0.90. SPADI also proved sensitive to differences in patients rating of perceived disability with $p$ value $<0.001 .^{21}$

A study done by Bicer et al, in 101 Turkish female patients showed a test-retest value of 0.92 and validated SPADI against visual analogue score (VAS) and health assessment questionnaire (HAQ) found correlation of coefficient for convergent validity 0.65 and 0.67 for VAS and HAQ respectively. ${ }^{28} \mathrm{~A}$ study done by Lacomba et al in 2015 , in 120 women who had undergone breast cancer surgery showed excellent reliability. Test-retest reliability was 0.992 for SPADI and 0.947 for OSS. High construct validity was found between the OSS and SPADI questionnaires $(\mathrm{r}=-0.674) .{ }^{29}$

Our study measured effectiveness of SPADI and OSS in 60 patients in the age group of 25-50 years. Effectiveness was tested by using the paired $\mathrm{T}$ test. It was found that the $\mathrm{t}$-scores of SPADI and OSS were similar $(\mathrm{t}=-19.3)$ and $\mathrm{p}$ value was significant $(<0.001)$ hence proving that both scores were equally effective in measuring the traits that is pain and disability in patients with shoulder pathology. The high Cronbach's alpha value in our study (Table 2) proves that SPADI scale is a reliable tool to measure both pain and disability traits in a patient with shoulder pathology. Validity study conducted by Tveita et al found SPADI to be unidimensional in patients with adhesive capsulitis. ${ }^{30} \mathrm{~A}$ similar result was interpreted inpatients recruited from orthopedic clinic in a study conducted by Roddey et al. ${ }^{31}$

A study on comparison of SPADI and OSS done by Dawson et al in UK analyzed these questionnaires by exploratory factor analysis (EFA) and confirmatory factor analysis (CFA) of data from 660 patients. On EFA, most OSS items loaded saliently on either of two "Pain" (4 items) and "Function" (8 items) factors, although some items cross-loaded. CFA suggested marginally better fit for two factors, with neither one- nor two-factor models rejected. EFA indicated two factors for the SPADI, with three of the eight "disability" items contributing to 8 items "pain factor", with 2 items within the 5 items "disability factor" cross-loading. CFA suggested marginally better fit for the two-factor (original conceptualization) model of the SPADI, with neither one nor two factor models rejected). Showing separate information on pain and selfreported disability/function can be extracted in a meaningful way, as subscales, from both the OSS and SPADI proving its bi dimensionality. ${ }^{32}$

Further the study conducted by Jeldi et al validated Tamil version of SPADI in Tamil population and has found higher internal consistency than the English version. ${ }^{33}$ Similarly, a study conducted by Rucha Gupta among the sweepers in the city of Surat found English SPADI as one of the biggest limitation in the study. ${ }^{34}$ In our study we would like to add that SPADI was more acceptable to our patients due to its ease and clarity but with limitation of its language.

\section{CONCLUSION}

In conclusion, this study proves the effectiveness of SPADI in given population by testing its validity with OSS. It proves the bi-dimensional aspect of SPADI scores. Further it also proves that SPADI is reliable, operationally simple and lucid for our population as compared to OSS.

Funding: No funding sources

Conflict of interest: None declared

Ethical approval: The study was approved by the institutional ethics committee

\section{REFERENCES}

1. Weevers HJA, Beek VAJ, Anema JR, Wal VG, Mechelen VW. Work related disease in general practice: A systematic review. Family Practice. 2005;22:197-204.

2. Roach KE, Budiman ME, Songsiridej N, Lertratanakul Y. Development of a shoulder pain and disability index. Arthritis Care Res. 1991;4:143-9.

3. Lippitt SB, Harryman DT, Matsen FA. A practical tool for evaluating function: the simple shoulder test. In: Matsen III FA, Fu FH, Hawkins RJ, eds. The 
shoulder:a balance of mobility and stability. Rosemont, Illinois: Am Acad Orthop Surgeons; 1993: 501-518.

4. Croft P, Pope D, Zonca M, Neill OT, Silman A. Measurement of shoulder related disability: results of a validation study. Ann Rheum Dis. 1994;53:525-8.

5. Richards RR, Ank N, Bigliani LU, Friedman RJ, Gartsman GM, Gristina AG, et al. A standardized method for the assessment of shoulder function. J Shoulder Elbow Surg. 1994;3:347-52.

6. Dawson J, Fitzpatrick R, Carr A. Questionnaire on the perceptions of patients about shoulder surgery. J Bone Joint Surg Br. 1996;78:593-600.

7. Kohn D, Geyer M. The subjective shoulder rating system. Arch Orthop Trauma Surg. 1997;116:324-8.

8. Insalata LJC, Warren RF, Cohen SB, Altchek DW, Peterson MG. A self- administered questionnaire for assessment of symptoms and function of the shoulder. J Bone Joint Surg Am. 1997;79:738-48.

9. Windt DAWM, Heijden GJ, Winter AF, Koes BW, Deville W, Bouter LM. The responsiveness of the Shoulder Disability Questionnaire. Ann Rheum Dis. 1998;57:82-7.

10. Heijden GJ, Leffers P, Bouter LM. Shoulder disability questionnaire design and responsiveness of a functional status measure. J Clin Epidemiol. 2005;53:29-38

11. Paul A, Lewis M, Shadforth MF, Croft PR, Windt DAWM, Hay EM. A comparison of four shoulderspecific questionnaires in primary care. Ann Rheum Dis. 2004;63:1293-9.

12. Deyo RA, Andersson G, Bombardier C. Outcome measures for studying patients with low back pain. Spine. 1994;19(18):2032-6.

13. Beaton DE, Richards RR. Measuring function of the shoulder. A cross- sectional comparison of five questionnaires. J Bone Joint Surg Am. 1996;78(6):882-90.

14. Dermid MJC, Solomon P, Prkachin K. Shoulder Pain and Disability Index demonstrates factor, construct and longitudinal validity. BMC Musculoskeletal Disord. 2006;7:12.

15. Williams JW, Holleman DR, SImel DL. measuring shoulder function with the Shoulder Pain and Diability Index. J Rheumatol. 1995;22(40):727-32.

16. Angst F, Goldhahn J, Drerup S, Aeschlimann A, Schwayzer HK, Simmen BR. Responsiveness of six outcome assessment instruments in total shoulder arthroplasty. Arthritis Rheum. 2008;59(3):391-8.

17. Headl SL, Riddle DL, Lamb RL. The shoulder pain and disability index: the construct validity and responsiveness of a region-specific disability measure. Phyd Ther. 1997;77(10):1079-89.

18. Schmitt JS, Fabio DRP. Reliable change and minimum important difference (MID) proportions facilitated group responsiveness comparison using individual threshold criteria. J Clin Epidemiol. 2004;57(10):1008-18

19. Staples MP, Forbes A, Green S, Buchbinder R. Shoulder-specific disability measures showed acceptable construct validity and responsiveness. J Clin Epidemiol. 2010;63(2):163-70.

20. Tevita EK, Ekeberg OM, Juel NG, Holter BE. Responsiveness of the shoulder pain and disability index in patients with adhesive capsulitis. BMC Musculoskeletal Disord. 2008;9:161.

21. Jamnik H, Spevak MK. Shoulder Pain and Disability Index: validation of Slovene version. Int J Rehabil Res. 2008;31:337-41.

22. Bumin G, Tuzun EH, Tonga E. The shoulder pain and disability index (SPADI): Cross-cultural adaptation, reliability and validity of the Turkish version. J Back Musculoskeletal Rehab. 2008;21:57-62.

23. Fries JF, Spitz P, Kraines RG. Measurements of patient outcome in arthritis. Arthritis Rheum. 1980;23:137-45.

24. Bot SD, Terwee CB, Windt VDA, Bouter LM, Dekker J, Vet HC. Clinicometric evaluation of shoulder disability questionnaires: a systemic review of literature. Ann Rheum Dis. 2004;63(4):335-41.

25. Roy JS, Dermid MJC, Woodehouse LJ. Measuring shoulder function: a systematic review of four questionnaires. Arthritis Rheum. 2009;61(5):623-32.

26. Streiner DL, Norman GR. Health measurement scales, a practical guide to their development and use. Oxford: Oxford university press; 21995.

27. Catherine LH, Susan L, Anne WT, Shanahan ME, Gill TK. Factor structure and validity of the shoulder pain and disability index in a population-based study of people with shoulder symptoms. BMC Musculoskeletal Disorder. 2011;12:8.

28. Bicer A, Ankarali H. Shoulder Pain and Disability Index: a validation study in Turkish women. Singapore Med J. 2010;51:865.

29. Maria TL, Beatriz S, Virginia PG, Soraya PDC. Spanish cultural adaptation and validation of the shoulder pain and disability index, and the oxford shoulder score after breast cancer surgery. Health Quality Life Outcomes. 2015;13:63.

30. Tveita EK, Sandvik L, Ekeberg OM, Juel NG, Holter BE. Factor structure of the Shoulder Pain and Disability Index in patients with adhesive capsulitis. BMC Musculoskelet Disord. 2008;9:103.

31. Roddey TS, Olson SL, Cook KF, Gartsman GM, Hanten W. Comparison of the University of California-Los Angeles Shoulder Scale and the Simple Shoulder Test with the shoulder pain and disability index: single- administration reliability and validity. Phys Ther. 2000;80(8):759-68.

32. Dawson J, Kristina KH, Helen D, Ray F, Carr A. A comparison of the Oxford shoulder score and shoulder pain and disability index: factor structure in the context of a large randomized controlled trail. Patient Related Outcome Measures. 2016;7:195-203.

33. Artaban JJ, Antony LA, Appaswami GD, Roach KE. Cross-cultural adaption, reliability and validity of an Indian (Tamil) version for the Shoulder Pain and Disability Index. Hong Kong Physiotherapy J. 2012;30:99-104. 
34. Gupta R. Reliability and validity of shoulder pain and disability index (SPADI) in sweepers of Surat city. Int $\mathrm{J}$ Yogic Human Movement Sports Sci. 2019;4(1):1231-6.
Cite this article as: Sukumar NPT, Manjunatha A. Shoulder pain and disability index: its effectiveness and reliability in an outpatient setting in Indian population. Int J Res Orthop 2020;6:671-7. 